\title{
Specialists' Register and Consultation Benefit in New Zealand
}

\author{
[From a SPecial CoRrespondent]
}

British Medical fournal, 1969, 4, 290-292

The year 1969 is likely to be a key date when the history of medicine in New Zealand is written. For then were introduced a register of specialists and a medical benefit for private consultations to specialists.* Neither of these events has created much stir and both are seen as long overdue reforms whose benefits are likely to outweigh any minor evils. There has been a long struggle to put specialist medicine on its feet and the present is understandable only in relation to the past. A register of specialists is nothing new, and South Africa has had one for many years.

New Zealand is made up of two large hilly islands whose total land area is a little bigger than that of the United Kingdom. Scattered along it are only 2.7 million people today, and 30 years ago there was a million less. The primary industry is the conversion of grass into animal protein and fat. In spite of this only a fifth of the people live in rural areas, and there are five urban areas with over 100,000 population each. Australia is 1,200 or so miles $(1,930 \mathrm{~km}$.) away, and New Zealand is well to the south of the main trans-Pacific sea and air routes.

The pattern of medical practice was set by the pioneer doctors who first came out some 120 years ago from the United Kingdom. Through necessity, you name it and he did itand well. There evolved hospitals in relation to centres of trade, and a common inter-hospital distance is about 50 miles $(80 \mathrm{~km}$.). Even in the largest towns prior to 1939 there were few, if any, who practised solely as specialists. The hospitals were staffed on the honorary system and were financed on the local rates.

\section{Social Security Act}

In 1935 the Labour Party was swept into power in wake of the Depression with a mandate to socialize wealth. A major reform in the Social Security Act was passed in 1938 which provided for superannuation, old age pensions, and widows and unemployment benefits. Also medical services were to be provided free at the source of supply. The medical profession were not unprepared for some sort of national health scheme, but the Government's proposals seemed to threaten the whole basis of medicine, that of professional freedom. There developed a bruising contest between the Government and the medical profession led by the B.M.A., and the nation was at war. Neither side really understood the other's point of view, and the wounds have taken a generation to heal. In the end, after what amounted to a strike by the doctors, the Social Security Act was amended in 1941. A fee for service system of payment was introduced at a fee of $7 \mathrm{~s}$. $6 \mathrm{~d}$. for each general medical service (G.M.S.). The doctor could charge above this.

*In New Zealand usage the word "consultant" is hardly used, and "specialist" is the word used for those who consult. A "consulting physician" is one who has retired from his hospital post.
Both sides had envisaged specialist services, but in the heat of the fight these were forgotten; anyway, there were few specialists, and many were overseas with the Services. Hospital treatment was to be free and the hospital specialists were to be paid on a sessional basis.

A feature of the medical benefits in New Zealand is that they are patient benefits and not direct benefits to the doctor, even if for administrative reasons the doctor collects the money from the State by a schedule. The G.M.S. benefit meant that a patient who saw a specialist privately could get $7 \mathrm{~s}$. $6 \mathrm{~d}$. from the State and had to pay the rest of the fee himself, which most are prepared to do. The quantum of $7 \mathrm{~s}$. $6 \mathrm{~d}$. (75 cents) has not been altered since its inception in 1941. The doctors cannot negotiate this, because the money is not directly paid to them ; it is the public who must squeal if ever the G.M.S. benefit is to be raised.

The 1941 compromise was not entirely without effect on the specialists. There was a maternity scheme, and for some special services obstetric competence had to be recognized, and there is an agreed list between the obstetricians and the Department of Health, which administers medical benefits.

Two specialties came out well, radiology and pathology. It was unlikely that the hospitals could provide enough of these services, and the private sector would be essential for the many patients seen outside the hospitals. Thus radiology and pathology became recognized, and there is an official list of those entitled to benefit from the particular schedules of the scheme. These specialties have turned out to be gold-plated ones, and the shortages here are not due to any lack of monetary reward. Further, radiology and pathology have become specialties where many of their members do practise entirely privately and without hospital appointments. This is unusual for other specialties.

\section{Private Practice}

The specialist with private practice is employed at a public hospital on a sessional basis, and the usual weekly content has been three. Recently five sessions have become common, and six or seven sessions may become the rule. Thus there is plenty of time for any other sort of practice. The bulk of their patients are seen in rooms, and large outpatient services at hospitals are the exception. The patient may be admitted to public hospital or put on the waiting-list without more ado. There are no private beds or wings in public hospitals, and private hospitals are entirely separate. The State subsidizes the cost of maintaining a private hospital bed but not the doctor's fee except for the G.M.S. benefit. The whole system is biased towards the private sector, particularly for the lesser illnesses and operations.

In view of the smallness of the population it is not surprising that the specialists have received much of their training abroad, 
usually in the United Kingdom. The Royal Australasian Colleges of Physicians and Surgeons both have their headquarters in Australia and are essentially run by Australians. While each College has a New Zealand committee with some autonomy, in the end the policy makers are in Australia and think in terms of Australian medicine. However, the Australasian diplomas now have a good status, and diploma hunting abroad carries no prestige. The major defect of the local diplomas or higher qualifications is that their donors have been unable to deal effectively with the local problems of training, which must go far beyond the mere granting of a diploma, and when some of it has still to be obtained overseas.

That the specialist sector of medicine had missed out on the social security benefits continued to rankle, and repeated representations by the B.M.A. (to become the Medical Association of New Zealand or M.A.N.Z. in 1967) made no impact upon the politicians. From the organizational point of view the specialists were divided among themselves and without any cohesive force. The first steps to a united front occurred in 1963, when an interim Central Specialists Committee (C.S.C.) was formed by interested groups of full- and part-time hospital specialists. At first the Royal Colleges were suspicious, and thought that their prerogatives might be encroached upon. The attitude of the B.M.A. was uncertain, as this Association had tended to be general-practitioner orientated. Gradually confidence was gained and the C.S.C. was formally established under the B.M.A. in 1966. Its terms of reference were all matters relating to specialist practice. This was awkward for the Royal Colleges, as their Royal Charters preclude them from being involved officially in salary negotiations. This was got around by having the Colleges as participating observers at C.S.C. meetings. From the start the main topics of C.S.C. have been specialists' registration and a specialists' benefit. While there was disagreement on the details there was none on the principles.

\section{Terms of Appointment}

What eventually put the C.S.C. on its feet was the setting up of a ministerial committee to advise on the unpopular terms of appointment for hospital staff. This Hospital Medical Officers' Advisory Committee will become a statutory committee in the near future. M.A.N.Z. through its C.S.C. is the recognized representative of the employees on this committee, and improved terms of hospital employment were negotiated in 1967. There is now a common definition of a hospital specialist, who has to be eight years qualified, have five years' practical experience in his specialty, and have a higher degree or diploma relevant to his specialty. Nothing is laid down about the type of training post to be held, nor of its quality. Not long after this C.S.C. set about compiling a list of acceptable higher qualifications which it intended to persuade the Department of Health to use for the Grading Committee, which regularizes hospital appointments.

It was necessary to revise the composition of the Medical Council of New Zealand in 1968, and in the ensuing bill the Council was enlarged and a Medical Education Committee added. The specialists had hoped that a register of specialists would also be included, but this was not in the first draft of the bill. At the committee stage M.A.N.Z. was able to make recommendations that such a register be added, and indeed it was surprised at this stage to find that the politicians were very desirous of this also. In the Medical Practitioners Act, 1968, there is a clause empowering the Medical Council to set up a register of specialists. The necessary regulations would appear as Orders in Council. It was widely believed that it would take at least a year to draft the new regulations and to mount the register after the new Council met in April, 1969.

Every three years there is a general election in New Zealand, which has some bearing on pre-election legislation-to say nothing of promises that can be made at the hustings. The end of November, 1969, is the date of the election. The next seemingly disconnected event was a meeting of the Minister of Health (Mr. D. N. McKay) with the Council of M.A.N.Z. in December, 1968. At first this appeared a public relations' exercise, but he made it clear that the G.M.S. benefit could not be raised on account of cost. However, there might be some other fields where small new medical benefits might apply. The Council informally expressed the hope that a specialist benefit might be one of these. At a meeting of the executive committee of M.A.N.Z. in March the Minister further aired some ideas about various medical benefits. The Minister was quite noncommittal, and many were not hopeful that anything would come of this.

\section{Register of Specialists}

Quite suddenly at the beginning of May the M.A.N.Z. was informed privately that new medical social security benefits were to be announced. Among these was a specialist consultation benefit. A public announcement about the new benefits was made on 14 May and the necessary legislation soon followed. Before there could be such a benefit there would have to be a register of recognized specialists. Time was short, as the new benefits were to come in on 1 October, 1969.

The newly reconstituted Medical Council had some qualms about mounting the register in time. Then followed a brief struggle between M.A.N.Z., the Department of Health, and the Medical Council as to who should make an interim specialists' register until the regulations could be gazetted. Fortunately sense prevailed, and the Medical Council found that it could do its official task. It had unexpected help from C.S.C., which was able to turn over all the data it had accumulated on higher qualifications to the Council and saving it much work.

Letters went out to the whole profession on 4 July asking them to apply for admission to a Provisional List of Specialists. There are 36 specialties and subspecialties including medical administration, public health, and general practice. The conditions for admission are not very precise, and state in general terms matters of training, experience, and qualification that allows provisional listing. By 1 October all those provisionally registered had been notified.

The specialist consultation benefit is paid when the patient is referred to a recognized specialist by another doctor, whether he be general practitioner or another specialist. A specialist who sees a patient without referral from another doctor-and there are many who do-claims the G.M.S. benefit ( 75 cents). Inter-specialty referral is allowed only with the concurrence of the referring doctor. The benefit is paid for the initial consultation under any one referral to a particular specialist. When the specialist is a physician, psychiatrist, neurologist, neura surgeon, or paediatrician the maximum benefit is $\$ 5.00$, and for all other specialists it is $\$ 3.50$. Of course, the specialist can charge any fee over and above this. The Government declined to insert any review mechanism for the quantum.

The specialists had always hoped that the register would come long before any specialist's benefit, as the vexed question of standards had to be solved. However, they were overtaken by events and got both in an election year. All would agree that this will hasten the transition to proper specialism in all fields of the profession.

\section{General Practice as Specialty}

A surprising inclusion in the list of specialties is general practice, and it is certain that the Government does not envisage paying a specialist consultation benefit to "specialist" general practitioners. The Medical Council has delayed calling for application to the Provisional List from general practitioners. It looks as if what is ultimately intended is a vocational register for the whole profession. This is in line 
with the Recommendations of the General Medical Council (in Britain) and similar ideas here, where it is realized that medical registration allows one to become trained for some vocational branch of the profession. This means that continuing postgraduate education for all doctors will be mandatory and a hope that it will not cease after vocational registration. The ultimate function of the register is the protection of the public.

It must be realized that under extreme pressure the Medical Council has produced a provisional list of specialists that can be used officially to implement a specialist consultation benefit. This gives breathing space for some of the implications of the register to be studied before the regulations are drafted and gazetted. The specialists hope that the criteria for admission to the register of specialists and those allowing for appointment as a hospital specialist will become one and the same.

It is known that there are some 950 hospital specialists, and if the number on the provisional list is much over 1,200 then the Medical Council has been more than generous to the foundation members. The most important task will be the laying down of adequate standards of training when so many specialists go abroad to finish their education. No one thinks that raising standards of training can be other than a long-term mission. For New Zealand these reforms are 30 years overdue, and, if vocational training is to have any sort of meaning, registration of specialists is an essential but minor requisite to be taken as a matter of course.

\title{
GENERAL PRACTICE OBSERVED
}

\section{Work of a Nurse in a Health Centre Treatment Room}

\author{
P. N. DIXON,* M.A., M.B., D.P.H.
}

\begin{abstract}
Cummary : In six months there were 1,704 attendances at the treatment room of a small health centre. The attendance rate for the population registered with the health centre doctors was 448 per 1,000 patients per year. Females between 15 and 44 years and males under 15 had the highest attendance rates. There were 256 casual attenders, $58(23 \%)$ of whom were referred to a doctor or hospital for further advice or treatment.

It is suggested that in a health centre treatment room about six hours of nursing time a week for every 1,000 patients is required, and that a case can be made out for some of the routine work of casualty departments being done in health centres.
\end{abstract}

\section{Introduction}

Every health centre in Bristol includes a treatment room which is staffed for up to 12 hours a day by State-registered nurses. The main function of these nurses is to assist the family doctors working in the health centres by undertaking practical nursing tasks, though the treatment rooms also come to be looked on by the local populations as convenient sources of professional advice. This report describes the work undertaken in the treatment room at one small health centre during the first six months of 1968.

\section{Material}

Stockwood Health Centre was opened in the autumn of 1967 in a newly developed area of the city. Seven family doctors from three practices work from the health centre, caring for about 7,500 patients. All have other surgery premises elsewhere.

The treatment room is staffed by sessional State-registered nurses from 8.30 a.m. to 5 p.m. from Monday to Thursday, and on Fridays until 1 p.m. In addition to working in the treatment room, the nurses assist as required in surgeries and clinics. Most of the time only one nurse is required, but on two mornings a week, when the demand from surgeries and clinics is particularly heavy, two nurses are normally present.
On Friday afternoons and Saturday mornings work in the treatment room is undertaken by members of the community nursing team established at the health centre (Dixon and Trounson, 1969). The State-enrolled nurse from this team also works in the treatment room from 5 to 8 p.m. on Thursdays, when for the most part she carries out repeat injections, dressings, and local skin treatments.

During the first six months of 1968 the nurses recorded certain information in respect of every attendance at the treatment room. The treatment given or action taken was described briefly on the record form and later coded by me, so as to eliminate differences in classification which might have arisen if this had been done by several different people. In some cases more than one item of service was provided for the same patient at a single attendance, but only the main item of service according to a predetermined order of precedence (see Table III) was used for the purposes of classification.

\section{Results}

\section{Pattern of Attendances}

During the six months of the study there were 1,704 attendances at the treatment room. The majority (57\%) were referred direct by the general practitioners, but $15 \%$ attended on their own initiative and a few were referred by other agencies or by one of the community nurses (Table I). Over a quarter were second or subsequent visits for completion of a course of treatment begun at the time of first referral or casual attendance.

TABLE I.-Source of Attendances at Treatment Room, fanuary to fune

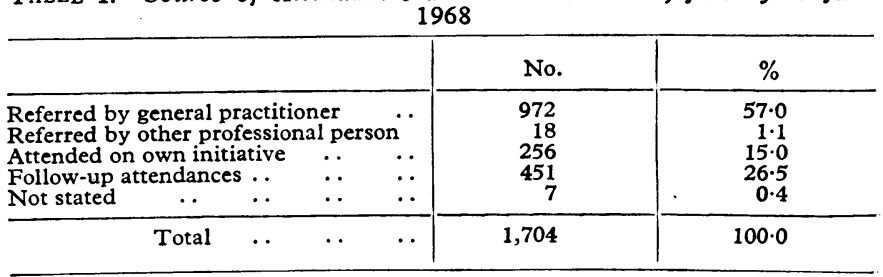

